It is not well recognized that promethazine can be given intravenously-for example, it is listed only for the oral and intramuscular routes in Wood's Paediatric Vade-Mecum. Promethazine needs to be diluted in water and is given here over a period of an hour by further diluting it with dextrose saline. Drowsiness is a common side effect, but despite this many of the children are able to leave hospital during the day. Repeated injections are avoided by using heparin locks -after the giving set has been disconnected heparin $100 \mathrm{U} / \mathrm{ml}$ is injected into a Butterfly intermittent infusion set or, even more satisfactory, into a male adapter plug connected to a short Teflon catheter.

Advances in the style of treatment may not affect the long-term outlook, but at least the burden is made less onerous for the children and their parents.-I am, etc.,

Department of Child Health,

P. J. KEARNEY Royal Hospital for Sick Children,

Bristol Wood, B., A Paediatric Vade-Mecum, 8th edn.
London, Lloyd-Luke, 1974.

\section{Treatment of D.I.C. Complicating}

Diabetic Coma

SIR,-I share the puzzlement of Drs. G. Nicholson and G. H. Tomkin (23 November, p. 450) concerning the few occasions when diabetes mellitus is complicated by disseminated intravascular coagulopathy (D.I.C.). Furthermore, it seems to me quite possible that even in their particular case the D.I.C. had actually nothing to do with the diabetes but was the complication of "thrombotic thrombocytopenic purpura" (T.T.P.).

What I am proposing is that their patient was "incubating" T.T.P., which put a mild diabetes out of control. Therefore at presentation it was the "out of control diabetes" which dominated the clinical picture. T.T.P. is a most unfortunate choice of name, since it refers to the complication of a disease instead of the disease itself. However, by this name I mean an especially fierce haemolytic process which is characterized by a degree of red cell fragmentation which, in my experience, is rarely seen when D.I.C. complicates other diseases.

Be that as it may, Drs. Tomkin and Nicholson have done a great service by emphasizing the value of high doses of heparin in the management of D.I.C. Three years ago I witnessed the death of a 19. year-old boy who developed D.I.C. following thrombosis of the spermatic vein. $\mathrm{He}$ was kept on low doses of heparin in spite of advice to the contrary. $-\mathrm{I}$ am, etc.,

Department of Haematology,

A. B. WEBER Stourbridge,

Pneumothorax Associated with Acupuncture

SIR,-Acupuncture is occasionally used in the treatment of intractable pain in the neck, shoulder, and arm. ${ }^{1}$ I wish to report an unexpected complication of its use in the shoulder region.

A slim 52-year-old woman developed a frozen left shoulder. As this did not respond to indomethacin or local analgesics she attended a health clinic where treatment by acupuncture was carried out. Fine solid needles (standard wire gauge 26 , shaft $2 \mathrm{~cm}$ ) were inserted in a line along the posterior aspect of the shoulder extending from the cervical spine to the acromion. On insertion of one needle she felt a severe generalized left-sided chest pain made worse by deep breathing. Four hours later she noticed that she became dyspnoeic on mild exertion. During the next two days her dyspnoea and chest pain gradually decreased, though there was no change in her shoulder pain. At the end of this time she attended this clinic and was found to have a generalized left pneumothorax which occupied one quarter of the area of the hemithorax on a posteroanterior radiograph.

It seems likely that the needle punctured the apical visceral pleura, producing a small hole which allowed the slow escape of air over a few hours. ${ }^{2}$ This hazard of needle insertion in the supraclavicular region is well recognized by anaesthetists who perform stellate ganglion or brachial plexus block by the posterior route. ${ }^{23}$ Dissections have shown that the lung apex in a thin subject may be less than $2 \mathrm{~cm}$ from the surface (C. S. Cairns, personal communication).

Doctors performing acupuncture in the shoulder region are warned to avoid inserting their needles to a depth of more than $0.5 \mathrm{~cm}$. - I am, etc.

Knightswood Chest Clinic,

B. H. R. STACK

Glasgow 1 Mann, F, et al., Lancet, 1973, 2, 57.
2 Macintosh, R., and Mushin, W. W. Local
Analgesia: Brachial Plexus, p. 58. Edinburgh,
Livingstone, 1967. Ostlere, M., Local Analgesia:
3acintosh, R., and Ostlere
Head and Neck, p. 132. Edinburgh, Livingstone,
1967.

\section{Safety and Fibreoptic Bronchoscopy}

SIR,-Dr. I. W. B. Grant (23 November, p. 464) has not questioned the safety of fibreoptic bronchoscopy but its adequacy in clinical practice. Our experience suggests that it is possible to undertake perfectly adequate examination with the fibreoptic bronchoscope under the same circumstances as with the rigid bronchoscope, provided one knows how to use it. Superficially this appears easy, but it is not, and as much experience is required as with the rigid bronchoscope. Furthermore, it is a dangerous assumption that an expert with the rigid bronchoscope will be equally expert with the fibreoptic bronchoscope, since the spatial orientation and maneouvring are totally different. We think there are few bronchoscopists who, because of inability to use the rigid bronchoscope, turn to the flexible bronchoscope as a soft option. If so, they are doomed to the disappointment, suggested in Dr. Grant's letter, of an inadequate examination.

With experience of nearly 200 fibreoptic bronahoscopies we find no difficulty in coping with bronchial secretions or bleeding, the small lens is perfectly easy to clean (by wiping, washing, and suction), and angulation of the tip impairs suction not at all (why should it?). In no patient has the procedure been unsuccessful because of these possible hazards. Furthermore, though the biopsy specimens are small, the positive yield with carcinoma of the bronchus has been high and the numbers missed through inadequate biopsy low and recognized.

In our hands we believe transnasal fibreoptic bronchoscopy under local anaesthesia to be relatively free from discomfort, and this view is based not only on experience with patients but also on experience with the technique on ourselves and in other centres. The simplicity of the technique, which is the key, has broadened the scope for what we term medical bronchoscopythat is, for conditions where subsequent surgery is unlikely. It has seemed unnecessarily complicated to use general anaesthesia in all but occasional patients. We have had no complications or complaints and several patients have undergone several bronchoscopies.

We believe it is misleading to label this procedure barbarous (though barbaric it may be in inexperienced hands). We think also that it goes without saying that no procedure shuld be undertaken by amateurs, however enthusiastic, and all should be undertaken by trained personnel. It is equally important that personnel are trained by those fully conversant with the techniques of handling these new instruments, and at the moment in Britain there appears to be a dearth of those suitably qualified. The techniques of rigid and fibreoptic bronchoscopy are complementary, but the fibreoptic bronchoscope alone has opened an exciting new field, the possibilities of which should not be underestimated.-We are, etc.,

S. W. Clarke

R. K. KNIGHT

Brompton Hospital,

London S.W. 3

\section{Advertising Consultant Posts}

SIR,- - The Medical Executive Committee of the Enfield District Hospitals wish to express their grave concern on one aspect of the Appointment of Consultant Regulations 1974, notified to us in Department of Health and Social Security Circular HSC(IS)24.

From this circular it appears that the Secretary of State is able to dispense with the requirement to advertise consultant posts. This is a retrograde step of the very first order. It has been one of the strengths of the hospital service, before and since 1948, that senior medical staff have a voice in the appointment of their colleagues. This results in ready acceptance of new colleagues and makes for smooth working within the hospital service. The system appears to have worked well and the reason for the change is not apparent.

In correspondence with the B.M.A secretariat we learn that the B.M.A. has had a meeting with the Department and has told them that in only very exceptional circumstances would there be agreement to appointments being filled without advertisement, and in any event there should be consultation with the profession before such action is taken. The object of this letter is to alert the profession to yet another restriction on our professional freedom, creeping in almost unnoticed in the small print of the massive piles of paper with which we are continually bombarded by the D.H.S.S.

Incidentally, a letter of protest to the Department, sent by me on 19 September, was acknowledged on 24 September and I was promised that "a further reply will be 